Fiscaoeconomia

E-ISSN: 2564-7504

2021, Volume 5, Issue 3, 1101-1116

https://dergipark.org.tr/tr/pub/fsecon
Research Article/Araştırma Makalesi

Submitted/Geliş: 12.08 .2021

Accepted/Kabul: 19.08 .2021

Doi: $10.25295 /$ fsecon.982198

\title{
Avrupa Birliği'nde Katma Değer Vergisi Uyumlaştırması
}

Value Added Tax Harmonization in the European Union

\section{Baki YEGEN ${ }^{1}$}

Öz

Ekonomik bütünleşme amacıyla kurulan Avrupa Birliği'nde vergisel anlamda ihtiyaç duyulan işbirliği, bütünleşme sürecinin önemli bir kısmını oluşturmaktadır. Bu nedenle üye ülkelerin vergi sistemlerinin yakınlaştııımalarına dolayısıyla da uyumlaştırma çalışmalarına intiyaç duyulmaktadır. Uyumlaştırma çalışmaları dâhilinde çoğunlukla Avrupa Birliği Konseyi tarafından yayınlanan direktifler kullanılmaktadır. Vergisel anlamda bütünleşmenin sağlanmasına yönelik yapılan uyumlaştırma çalışmalarında diğer vergi türlerine kıyasla Katma Değer Vergisi'nin ön planda tutulduğu yayınlanan direktiflerden anlaşılmaktadır. Katma Değer Vergisi ile ilgili uyumlaştırma çalışmaları kapsamında geçmişten günümüze çok sayıda direktif yayınlanmış olup, çalışmada söz konusu direktifler içerisinden ortak katma değer vergisi sistemi üzerinde belirleyici olan direktifler incelenmiştir. Çalışmada incelenen direktiflerde belirlenen kurallar göz önünde bulundurularak üye ülkelerde katma değer vergisi kapsamında uygulanmakta olan indirilmiş oranlar, süper indirilmiş oranlar, standart oranlar ve yaklaştırma oranları karşılaştıııııştır. Karşısaştırma sonucunda Avrupa Birliği'nde katma değer vergisinin uyumlaştıııımasında önemli aşama kaydedilmiş olmasına karşın oran konusunda hâlen önemli farklılıkların mevcut olduğu anlaşılmışır.

Jel Kodları: H2O, H22, K34.

Anahtar Kelimeler: Avrupa Birliği, KDV, Vergi Uyumlaştırması.

\footnotetext{
${ }^{1}$ Dr. Öğr. Üyesi, Niğde Ömer Halisdemir Üniversitesi, iktisadi ve İdari Bilimler Fakültesi, Maliye Bölümü, bakiyegen@ohu.edu.tr, ORCID: 0000-0003-4118-1445
}

Citation/Atıf: Yegen, B. (2021). Avrupa Birliği'nde Katma Değer Vergisi Uyumlaştırması. Fiscaoeconomia, 5(3), 1101-1116. Doi: 10.25295/fsecon.982198 


\begin{abstract}
The cooperation needed in the tax sense in the European Union, which was established for the purpose of economic integration, constitutes an important part of the integration process. For this reason, there is a need for the approximation of the tax systems of the member states and thus harmonization studies. Within the scope of harmonization studies, the directives published by the Council of the European Union are mostly used. It is understood from the published directives that Value Added Tax is prioritized compared to other tax types in harmonization studies aimed at ensuring taxation integration. Within the scope of harmonization studies related to Value Added Tax, many directives have been published from the past to the present, and the directives that are determinative on the common value added tax system among these directives have been examined in the study. Considering the rules determined in the directives examined in the study, the reduced rates, super-reduced rates, standard rates and parking rates applied within the scope of value added tax in member countries were compared. As a result of the comparison, it is understood that although significant progress has been made in the harmonization of value added tax in the European Union, there are still significant differences in the rate.
\end{abstract}

Jel Codes: H2O, H22, K34.

Keywords: European Union, VAT, Tax Harmonization.

\title{
1. Giriş
}

Dünyanın en önemli ekonomik topluluklarından biri olarak faaliyet gösteren Avrupa Birliği (AB) başlangıçta altı üye devletin bir araya gelmesiyle kurulmuş olup zamanla yaşanan genişlemelere bağlı olarak günümüzde yirmi yedi üye devletten oluşmaktadır. Bünyesinde farklı devletleri barındıran ve uluslar üstü bir örgüt olan $A B$, üye devletlerin ekonomik açıdan menfaatlerini gözeterek kolektif çıkar amacıyla hareket etmektedir. Ekonomik bütünleşmenin hayata geçirilmesi hususunda $A B$ ortak pazar oluşturmak için yıllar içerisinde somut adımlar atmıştır. Ortak pazar sayesinde "dört özgürlük" olarak bilinen malların, hizmetlerin, kişilerin ve sermayenin birlik içerisinde serbest şekilde hareket etmesi öngörülmektedir. Ancak ortak pazarın etkin bir şekilde uygulanabilmesi vergisel anlamda uyumlaştırma çalışmalarını gerekli kılmaktadır. Bu noktada uyumlaştırma çalışmalarında birliğin ortak tüketim vergisi olarak kabul edilen Katma Değer Vergisi'nin (KDV) uyumlaştırılmasına öncelik verildiği anlaşılmaktadır.

\section{2. $A B^{\prime}$ de Vergi Uyumlaştırması ve Nedenleri}

Vergilerin yasal olarak belirlenmeleri, yapılış esasları ve tahsil şekilleri vergi sistemini oluşturmaktadır. Vergi sistemi; vergiler kümesini ve devlete yapılan zorunlu ödemeleri temsil eder. Ayrıca ilkeleri, kuruluş şekil ve yöntemlerini, değişiklik, iptal, tahsilat, vergi hesaplama ve denetim unsurlarını da temsil eder. Ülkelerdeki vergi sistemleri yapı, sayı, vergi matrahı, tahsil yöntemleri, vergi oranları ve vergi avantajları gibi hususlarda farklılık gösterebilir. Vergi sistemlerinin farklı ekonomik, politik ve sosyal koşullardan etkilenerek evrimleştiği ve gelişmeye devam ettiği düşünüldüğünde ülkeler arasında vergi sistemlerinin farklılık göstermesi beklenen bir durumdur (Safonova vd., 2016: 155-156). Her ülkede işleyen vergi 
Yegen, B. (2021). Avrupa Birliği'nde Katma Değer Vergisi Uyumlaştırması. Fiscaoeconomia, 5(3), 1101-1116. Doi: 10.25295/fsecon.982198

sistemlerinin kendilerine has özellikleri bulunmakla birlikte esas sorun ülkelerdeki vergi, yasal düzenlemelerin ve mevzuatların farklılığıdır (Hodzic ve Celebi, 2017: 80).

Ekonomik entegrasyondan söz edebilmek için haksız rekabet yaratacak vergi sistemlerinin gözden geçirilmelerine ihtiyaç duyulmaktadır. Bu nedenle ortak pazar anlayışının benimsendiği $A B^{\prime}$ de birliğe üye ülkeler arasındaki vergi sistemi kaynaklı farklılıkların giderilmeleri öncelikli olarak hedeflenmektedir (Oral, 2005: 261). Farklı vergi sistemlerini yeknesaklaştırmak mümkün olmamakla birlikte, söz konusu sistemleri kademeli olarak birbirlerine yakınlaştırmak mümkün olmaktadır. Bu noktada vergi uyumlaştırması kavramı karşımıza çıkmaktadır.

Çoğunlukla üye ülkelerin vergi sistemlerinin yakınsaması anlamında kullanılan vergi uyumlaştırması kavramı vergi teorisinde çeşitli şekillerde tanımlanmaktadır (Nerudová, 2004: 136). Bu kapsamda vergi uyumlaştırması, ortak kurallar çerçevesinde vergi sistemlerinin ayarlanmak suretiyle ortak bir noktada birleştirilmesi süreci olarak tanımlanabilmektedir (Alganer ve Yılmaz, 2010: 138). Bir diğer tanıma göre vergi uyumlaştırması; ortak serbest piyasanın etkin şekilde çalışmasına mâni olan vergi uyumsuzluklarını ortadan kaldırmak için devletlerin hukuki ve idari düzenlemelerle ortak vergi politikaları hedeflerine uygun şekilde hareket etmeleri olarak tanımlanabilir (Yıldız, 2004: 49). Üye ülke ekonomilerinin entegrasyonunu sağlamak için vergi sistemlerindeki önemli farklılıkların ortadan kaldırılması anlamına gelen vergi uyumlaştırması, üye ülkeler arasında kaynak tahsisinde etkinliğin sağlanmasına yardım etmektedir (Karolak, 2011: 55). AB açısından karmaşık bir konu olan vergi uyumlaştırması, vergi sistemlerinin karşılıklı bir dizi kurala dayalı olarak yakınsama süreci olarak da ifade edilmektedir. Vergi uyumlaştırması kapsamında vergi oranlarının aynı olması toplam açık vergi uyumlaştırması, en yüksek ve en düşük vergi oranlarının belirlenmesi anlamına gelen benzer olması ise kısmi açık vergi uyumlaştırması olarak adlandırılmaktadır (Kozuharov vd., 2015: 255). Her ne şekilde olursa olsun vergi uyumlaştırmasıyla ulusal vergi uygulamaları uluslararası bir güç tarafından yönlendirilmekte, böylelikle bir anlamda vergilendirme yetkisi uluslararası bir güçle paylaşılmaktadır. Bu nedenle $A B$ 'de üye ülkeler vergi sistemlerini topluluk amaçları doğrultusunda düzenlemekle yükümlü olmaktadırlar (Erkan, 2009: 29). AB'ye üye ülkeler açısından birlik mevzuatı, uymaları gereken üst bir hukuki norm olmasının yanı sıra üye ülkelerin mevzuatlarını birlik mevzuatına yakınlaştırmalarına da rehber olmaktadır (Güçlü, 2012: 134).

Vergi uyumlaştırması kavramının temelinde farklı vergi sistemlerine sahip üye ülkelerin sebep olacakları rekabeti bozucu vergi uygulamalarının önüne geçilmesi fikri yatmaktadır. Çünkü ülkelerin sahip oldukları farklı vergi uygulamaları vergi eşitsizliklerine yol açmakta ve ekonomik bütünleşmenin gerçekleşmesine engel olmaktadır. Bu nedenle farklı vergi mevzuatı bulunan ve bunun bir sonucu olarak farklı vergi yüklerinin geçerli olduğu ülkelerin vergi konusunda iş birliği yapmalarına ihtiyaç duyulmaktadır (Altunay, 2010: 97-98). AB içindeki entegrasyon, ilişkilerin neredeyse tüm taraflarını siyaset, ekonomi, sosyal ve kültürel alanlarda etkilemektedir (Safonova vd., 2016: 154). Şöyle ki üye ülkelerden bir tanesinin dahi vergi eşitsizliği yaratacak vergi uygulamasına sahip olması diğer üye ülkeleri olumsuz etkileyebilmektir. Bu yüzden vergi uyumlaştırması konusunda birliğe üye bütün ülkelerin uyum içinde hareket etmeleri gerekmektedir. Vergi eşitsizliğine ise üye ülkelerde uygulanan farklı vergi oran, matrah, istisna, indirim ve muafiyet uygulamaları yol açabilmektedir. 


\begin{abstract}
$\mathrm{AB}^{\prime}$ de vergi uyumlaştırmasının çeşitli nedenleri bulunmakta olup bunlar; tek pazarın etkin işleyişini teşvik etmek, vergi geliri kayıplarının önlenmek, çifte vergilendirme ve vergi kaçakçılığı olasılığının ortadan kaldırmak, zararlı vergi rekabetinden kaçınmak ve kaynak tahsisinde bozulmaları önlenmektir (Matei ve Pirvu, 2011: 66-73). Anlaşıldığı üzere $A B^{\prime}$ de vergi uyumlaştırmasının nedenleri ağırlıklı olarak birliğin ekonomik amaçlarına hizmet etmeye yöneliktir.
\end{abstract}

\title{
3. Avrupa Birliği KDV Uyumlaştırma Çalışmaları
}

$A B^{\prime}$ de tarafsız bir rekabet ortamının oluşturulması amacıyla üye ülkelerin vergi politikalarını rekabet ortamına zarar vermeyecek şekilde belirlemeleri gerekmektedir. Bu nedenle birlik dâhilinde uzun zamandır uyumlaştırma çalışmaları yapılmaktadır (Yıldız, 2006: 549). Üye ülkelerin egemenlik güçleri dâhilinde vergilendirme yetkilerini özgür şekilde kullanmak istemeleri $A B^{\prime}$ nin ekonomik bütünleşmeyi öngören kuruluş amaçlarına ters düşmektedir. $A B^{\prime}$ ye üye ülkeler vergilendirme yetkilerini paylaşmaya istekli olmadıkları için dolaysız vergilerin uyumlaştırma çalışmaları ön planda tutulmamıştır (Albayrak ve Yurdadoğ, 2017: 5154). Bunun yerine uyumlaştırma çalışmalarında işlevsel ve etkin bir ortak pazara ulaşmak amacıyla ekonomik konuların neredeyse tüm faaliyetleriyle çok yakından bağlantılı aynı zamanda iç pazardaki işleri önemli ölçüde etkileme gücü olan dolaylı vergilere ağılık verilmiştir (Nerudová, 2004: 137).

Avrupa Birliği'nin kuruluşu Avrupa Kömür ve Çelik Topluluğu'nun oluşturulduğu 1951 yılında imzalanan Paris Antlaşması'na dayanmakla birlikte birlikle ilgili temel hususlar Avrupa Ekonomik Topluluğu'nun oluşturulduğu 1957 yılında imzalanan Roma Antlaşması'yla belirlenmiştir. Avrupa Birliği'nde iktisadi entegrasyonun hukuki temellerinin atıldığı antlaşmalardan biri olan 25 Mart 1957 tarihli Roma Antlaşması'nın 93. maddesinde ${ }^{2}$ dolaylı vergi uyumlaştırmasından bahsedilmektedir (Oral, 2005: 263).

"Konsey, Komisyonun önerisi üzerine ve Avrupa Parlamentosunun görüşünü aldıktan sonra oybirliğiyle, muamele vergileri, özel tüketim vergileri ve diğer tür dolaylı vergilere ilişkin mevzuatın uyumlaştırılmasına yönelik hükümleri, bu uyumlaştırmanın 14. maddesinde öngörülen sürede iç pazarın kurulmasını ve işleyişini sağlaması için gerekli olduğu ölçüde kabul eder."

Vergileri birleştirme hedeflerini karşılayan 93. maddede dolaylı vergilerin uyumlaştırılması ortak pazarın gerçekleştirilmesi için vazgeçilmez bir koşul olarak öngörülmektedir (Karolak, 2011: 56). Bu nedenle 93. madde aracılığıyla fiyatlar üzerinde belirleyici özelliğe sahip dolaylı vergilerin üzerinde durulduğu anlaşılmaktadır. Üye ülkelerin satış vergileri aracılığıyla ticareti ve rekabeti olumsuz şekilde etkilemelerini önlemek amacıyla Avrupa Ekonomik Topluluğu'nun kurulduğu Roma Antlaşması'na müteakiben dolaylı vergilere yönelik uyumlaştırma çalışmalarına başlanmıştır (Güngör, 2001: 55). Anlaşıldığı üzere uyumlaştırma çalışmaları çoğunlukla dolaylı vergilere yönelik olmuştur. Bunun nedeni ortak pazar düşüncesinin hayata

\footnotetext{
22 Ekim 1997 tarihli Amsterdam Antlaşmasıyla değiştirilmeden önce Roma Antlaşması'nın 99. maddesinde
} düzenlenmektedir. 
Yegen, B. (2021). Avrupa Birliği'nde Katma Değer Vergisi Uyumlaştırması.

Fiscaoeconomia, 5(3), 1101-1116. Doi: 10.25295/fsecon.982198

geçirilmesinde dolaylı vergilerin önemli bir yere sahip olmasıdır. Dolaylı vergilerden ise özellikle KDV üzerinde durulmuş, uyumlaştırma çalışmaları KDV üzerinde yoğunlaşmıştır (Yazarkan ve Mezararkalı, 2015: 64). Nitekim uyumlaştırma konusunda en büyük gelişme KDV alanında sağlanmıştır (Hodzic ve Celebi, 2017: 80). Uyumlaştırma çalışmalarında KDV'ye öncelik verilmesinin nedenini şu şekilde açıklayabiliriz. KDV mal teslimlerini ve hizmet ifalarını kapsayan geniş tabanlı bir vergi türüdür, bu durum ise mal ve hizmetlerin serbest hareket etmelerine engel olabilmektedir. Diğer bir ifadeyle üye ülkelerin farklı KDV uygulamaları uyumlaştırma yapılmadığı takdirde haksız vergi rekabetine yol açabilmektedir.

Roma Antlaşmasıyla uyumlaştırma konusunda genel çerçeve belirlenmiş olup, detaylarla ilgili açıklamalara yer verilmemiştir. Ülkelerin vergi politikaları ekonomik ve sosyal faktörlere göre farklılık gösterdiği için ortak vergi politikalarının belirlenmesi ve üye ülkelerin ortak politikalara uyum sağlayacak şekilde vergi mevzuatlarını düzenlemeleri öngörülmüştür. Bu yüzden Roma Antlaşmasıyla ülkelerin vergilendirme yetkileri kendilerine bırakılmış olup, gerektiğinde söz konusu yetkilerin birlik gözetiminde çıkarılan tüzük, direktif ve kararlar aracılığıyla paylaşılabileceği vurgulanmıştır (Altunay, 2010: 95). Tüzük, direktif ve kararların bağlayıcı özellikleri bulunmakla birlikte birlik tarafından üye ülkelere tavsiye ve görüşler de bildirmektedir. Ancak söz konusu vergi düzenlemeleri arasında en fazla direktifler tercih edilmektedir (Erkan, 2009: 29).

\section{AB KDV Rejiminin Yürürlüğe Girişi}

Roma Antlaşması'nın imzalanmasından sonra uyumlaştırma çalışmalarına hız verilmiş ve 1960 yılında Vergi ve Maliye Komitesi diğer ismiyle Neumark Komitesi kurulmuştur. Komite tarafından 1962 yılında sunulan Neumark Raporu ise KDV uyumlaştırmasına yön vermiştir (Saraçoğlu, 2006: 35). 1960'lı yıllarda Avrupa'da sadece Fransa'da KDV, diğer ülkelerde yayılı muamele vergisi olmak üzere iki tip vergi uygulandığı için Neumark Raporu'nda bu husus üzerinde durulmuştur. Yayılı muamele vergisinde üreticiden tüketiciye iktisadi sürecin her aşaması vergiye tabi olmakta diğer bir ifadeyle vergi üzerinden vergi alınmasına karşın KDV'de vergi her aşamada ortaya çıkan katma değer üzerinden alınmakta ve alışlarda ödenen verginin satışlarda tahsil edilen vergiden indirilmesine imkân tanınmaktadır. Bu özelliğiyle KDV yayılı muamele vergisine kıyasla daha tarafsı bir vergi türü olarak kabul edilmektedir (Ünsal ve Ubay, 2018: 277). Bu noktadan hareketle Neumark Rapor'unda dolaylı vergiler alanında uygulanan farklı vergi türlerinin rekabeti ve ortak pazarın işleyişini olumsuz etkileyeceği düşüncesiyle birlik dâhilinde genel harcama vergisi olarak KDV'nin uygulanması önerilmiştir. Bu yönde yapılan uyumlaştırma çalışmaları dâhilinde 1967 yılında yayınlanan 1. Direktif ve 2 . Direktifle uyumlaştırma çalışmaları fiilen başlamış ve birliğin ortak tüketim vergisi olarak KDV'nin 1970 yılında uygulanması öngörülmüştür. KDV ile ilgili uyumlaştırma çalışmaları 1977 yılında yayınlanan Altıncı Direktif, 16 Aralık 1991 tarihli Direktif, 16 Aralık 1996 tarihli Direktif ve 28 Kasım 2006 tarihli konsey Direktifiyle devam etmiştir (Alganer ve Yılmaz, 2010: 142). $A B^{\prime}$ de ortak bir KDV sistemine geçilmesi amacıyla 1967 yılından itibaren çok sayıda direktif yayınlanmış olup tam anlamıyla vergi uyumlaştırması sağlanıncaya kadar gelecek yıllarda da çok sayıda direktif yayınlanacağı kolayca tahmin edilmektedir. Günümüze değin yayınlanan direktifler dikkate alındığında ortak KDV sisteminin temelinin atılmış olduğu ve sistemin bugünkü halini almasında belirleyici olan en önemli konsey direktiflerine aşağıda alt başlıklar halinde kısaca değinilmektedir. 


\subsection{Birinci Konsey Direktifi}

11 Nisan 1967 tarihinde yayınlan birinci konsey direktifinde (67/227/CEE) üye devletlerin muamele vergilerine ilişkin mevzuatlarının uyumlaştırılmasıyla ilgili açıklamalara yer verilmiştir. Bu kapsamda üye ülkelerin farklı vergi türlerinden vazgeçerek ortak bir KDV sistemini benimsemeleri gerektiği ifade edilmiştir. KDV'nin ortak pazarın ve üye ülkelerin çıkarlarına hizmet edeceği belirtilmiştir. 1 Ocak 1970 tarihine kadar ülkelerin mevzuatlarında gerekli değişiklikleri yapmaları gerektiği direktifin 1 . maddesinde açıkça ifade edilmiştir. Direktifin 2. maddesinde ise ortak katma değer vergisi sistemi ilkesinden bahsedilmiştir. Buna göre üretimden dağıtıma her aşamada işlem sayısına bakılmaksızın mal ve hizmetlerin fiyatlarıyla orantılı olmak üzere tüketim üzerinden genel bir vergi alınacağı ifade edilmiştir.

\section{2. İkinci Konsey Direktifi}

Birinci direktifle aynı tarihinde yayınlan ikinci konsey direktifi (67/228/EEC) ortak katma değer vergisi sisteminin yapısı ve uygulama usulüne ilişkindir. Bir diğer ifadeyle ikinci direktifle KDV'nin temel unsurları belirlenmiştir. Bu kapsamda ikinci direktifte KDV'nin konusu, uygulanacağı bölge, mükellefi, teslim ve teslim sayılan haller, hizmet ve hizmet sayılan haller, mal ithalatı, matrah, standart oran, indirimli oran, muafiyet, istisna ve indirimlere ilişkin açıklamalara yer verilmiştir.

\subsection{Altıncı Konsey Direktifi}

17 Mayıs 1977 tarihinde yayınlan altıncı konsey direktifinde (77/388/EEC) üye devletlerin mevcut katma değer vergisi sistemlerini direktifte belirtilen hususlara göre değiştirmeleri gerektiği ifade edilmiştir. Kanun, yönetmelik ve idari hükümleri içeren muhtemel değişikliklerin en geç 1 Ocak 1978 tarihine kadar tamamlanmaları gerektiği belirtilmiştir. Ayrıca söz konusu direktifte tanıtıcı hükümler, bölgesel uygulamalar, mükellefler, vergilendirilebilir işlemler, vergilendirilecek işlemlerin yeri, vergiyi doğuran olay ve verginin ödenmesi, vergilendirilebilir tutar, oranlar, istisnalar ve muafiyetler, indirimler, vergi ödeme sorumlulukları, ödeme sorumlu kişilerin yükümlülükleri, özel hususlar, sadeleştirme prosedürleri, geçici hükümler, katma değer vergisi komitesi, çeşitli hükümler ve nihai hükümlere ilişkin detaylı açıklamalara yer verilmiştir.

Altıncı direktif ikinci direktifle benzer hususları düzenlemesine karşın ikinci direktiften daha geniş bir düzenleme alanına sahip olmuştur. Altıncı direktifin yayınlanmasıyla birlikte üye ülkeler tüketim tipi KDV'ye geçmiş ve dış ticarette varış ülkesinde vergilendirme ilkesini benimsemişlerdir (Saraçoğlu ve Ejder, 2002: 65). Varış ülkesinde vergilendirme ilkesine göre ülkelerden ihraç amacıyla çıkan mallara ait genel tüketim vergilerine ilişkin vergilendirme işlemlerini malı gönderen ülke değil, teslim alan ülke üstlenmektedir (Pehlivan ve Öz, 2015: 22). Ayrıca direktifle birlikte üye ülkelere standart oranın yanı sıra bazı durumlarda artırılmış veya azaltılmış oranlar uygulama imkânı sunulmuştur.

\subsection{Aralık 1991 Tarihli Konsey Direktifi}

Avrupa Komisyonu Beyaz Kitapları, belirli bir alanda birliğin eylemi için öneriler sunmakta ve taraflara siyasi uzlaşma olanağı sağlamaktır. Zaman içinde komisyon tarafından günümüze değin çok sayıda (46 tane) beyaz kitap yayınlanmıştır. Beyaz kitaplar içerisinde 1985 yılında yayınlanan beyaz kitap, iç pazarın tamamlanmasını konu edinmiştir. Bu noktada ilgili kitapta 
Yegen, B. (2021). Avrupa Birliği'nde Katma Değer Vergisi Uyumlaştırması. Fiscaoeconomia, 5(3), 1101-1116. Doi: 10.25295/fsecon.982198

fiziksel engellerin kaldırılması, teknik engellerin kaldırılması ve mali engellerin kaldırılması konularına değinilmiştir. Söz konusu beyaz kitap, konsey tarafından kabul görmesi ve alandaki mevzuatın kabul edilmesine katkı sağlaması sebebiyle önemli bir yere sahip olmuştur (www.eur-lex.europa.eu). 1985 yılında Beyaz Kitap konsey tarafından kabul gördükten sonra birlik, 1993 yılına kadar tek pazarı devreye sokmayı amaçlamıştır (www.ab.gov.tr). Nihayet 1 Temmuz 1987 tarihinde Tek Senet yürürlüğe girmiş ve Tek Senet'le üye ülkelerin yasal düzenlemelerinin uyumlaştırılmasına ilişkin yöntem ve araçlar tanımlanmıştır (Karolak, 2011: 55). Söz konusu belgeyle birlikte Tek Pazar; sınırların kaldırıldığı ve malların, hizmetlerin, sermayenin ve kişilerin serbest dolaşımının sağlanacağı bir alan olarak tanımlanmıştır. Böylece Avrupa'da sınırların kaldırılacağına işaret edilmiştir. 21 Ağustos 1987 tarihli Cockfield Raporunda Tek Pazar'da KDV'nin uygulamasına yönelik öneriler sunulmuştur. Söz konusu öneriler ışığında ise 16 Aralık 1991 tarihli Direktif hazırlanmıştır (Bilici, 2007: 187).

16 Aralık 1991 tarihli konsey direktifi (91/680/EEC) altıncı konsey direktifini değiştirmek, ortak katma değer vergisi sistemini tamamlamak ve mali sınırları ortadan kaldırılmak amacıyla yayınlanmıştır. Bu kapsamda altıncı konsey direktifinin üçüncü, yedinci, sekizinci, onuncu, on birinci, on dördüncü, on beşinci, on altıncı, on yedinci, on sekizinci, yirmi birinci, yirmi ikinci, yirmi beşinci, yirmi sekizinci ve otuz üçüncü maddelerinde değişiklikler yapıımıştır. Ayrıca yine altıncı konsey direktifinde yer alan sekizinci, on birinci, on beşinci, on altıncı, yirmi dördüncü, yirmi beşinci ve yirmi sekizinci maddelere eklemeler yapılmış, on birinci ve on dördüncü maddelerin bazı kısımları ise silinmiştir.

\subsection{Ekim 1992 Tarihli Konsey Direktifi}

$A B^{\prime}$ de KDV uyumlaştırma çalışmaları kapsamında yayınlanan bir diğer önemli direktif (92/77/EEC) 19 Ekim 1992 tarihinde yayınlanmıştır. Söz konusu direktifle ortak katma değer vergisi sistemini tamamlamak ve altıncı konsey direktifini (77/388/EEC) değiştirmek (KDV oranlarının yaklaştırılmaları) amaçlanmıştır. Bu kapsamda altıncı konsey direktifinin on ikinci ve yirmi sekizinci maddelerinde değişiklikler yapılmıştır.

19 Ekim 1992 tarihli konsey direktifiyle oranlar alanında ana hükümleri olan bir "geçiş" sistemi kabul edilmiş ve üye devletlerin;

- 1 Ocak 1993 tarihinden itibaren \%15'ten az olmayan standart bir oran uygulamaları,

- Yalnızca Ek H'de belirtilen mal ve hizmet kategorilerinin tedariki için geçerli olacak ve $\% 5$ ten az olmayacak şekilde bir veya iki indirimli oran uygulayabilmeleri,

- Kesin bir KDV sistemi getirilene kadar bazı üye devletlerin sıfır, süper indirimli ve yaklaştırma oranları uygulayabilmeleri

- "Lüks" veya daha yüksek oranların kaldırılmaları öngörülmüştür.

Söz konusu direktifin ardından komisyon maksimum \%25'lik bir oranın getirilmesi için COM(1995)73 ve COM(1998)693 olmak üzere iki girişimde bulunmuş ancak girişimler konsey tarafından reddedilmiştir (Patterson, 2003: 5).

\subsection{Kasım 2006 Tarihli Konsey Direktifi}

illk olarak 1967 yılında çıkarılan iki direktifle başlayan ortak KDV sistemi oluşturma çabaları yıllar içerisinde yayınlanan çeşitli direktiflerle devam etmiştir. AB'de KDV uyumlaştırması 
Yegen, B. (2021). Avrupa Birliği'nde Katma Değer Vergisi Uyumlaştırması. Fiscaoeconomia, 5(3), 1101-1116. Doi: 10.25295/fsecon.982198

kapsamında yayınlanan en önemli direktiflerden biri (2006/112/EC) de 28 Kasım 2006 tarihli konsey direktifidir. 28 Kasım 2006 tarihli konsey direktifiyle ortak KDV sistemi hemen hemen son şeklini almış olup, sonraki yıllarda sistemde sadece detaylara ilişkin değişiklikler yapılmıştır (Güçlü, 2012: 134). Nitekim AB KDV sistemine ilişkin şu anda yürürlükte olan ana düzenlemeler söz konusu direktifte yer almaktadır (Oręziak, 2020: 97). Bir diğer ifadeyle 28 Kasım 2006 tarihli konsey direktifiyle ortak bir KDV sistemi oluşturmaya yönelik mevzuatın ana çerçevesi oluşturulmuştur (Hodzic ve Celebi, 2017: 81). Söz konusu direktifle ortak katma değer vergisi sistemi ile ilgili mevzuatın tek bir belge altında toplanmasına yönelik düzenlemeler yapıımıştır (Alganer ve Yılmaz, 2010: 151). Bu kapsamda altıncı konsey direktifi yürürlükten kaldırılmış ve birkaç kez önemli ölçüde değiştirilen ortak KDV sistemi sadeleştirilmiştir.

\section{AB'de Oran Açısından Uyumlaştırma}

$A B^{\prime}$ de ortak bir genel harcama vergisi olarak KDV'nin önerilmesi 1967 yılında yayınlanan birinci konsey direktifine dayanmakla birlikte takip eden direktiflerde KDV ile ilgili temel unsurlara ilişkin açıklamalara yer verilmiştir. Temel unsurlardan biri de oran olup, tıpkı KDV'de olduğu gibi ad valorem matrah esasının benimsendiği vergi türlerinde verginin tarh etmesinde matrahla birlikte oran/oranlara ihtiyaç duyulmaktadır. Bu kapsamda altıncı konsey direktifinde ilk kez azaltılmış oran kavramına yer verilmiştir.

Avrupa Birliği'nde uygulanması öngörülen ortak KDV sisteminin oran yapısına ilişkin ilk detaylı düzenlemeye ise 19 Ekim 1992 tarihli konsey direktifinde yer verilerek altıncı direktifte önemli değişiklikler yapılmıştır. Şöyle ki altıncı konsey direktifinin 1977 tarihinde yayınlan ilk halinde KDV'nin oran yapısı ile ilgili herhangi bir ifadeye yer verilmemişken 19 Ekim 1992 tarihli konsey direktifiyle KDV'nin oran yapısı belirlenmiş ve yıllar içerisinde yayınlanan direktifler aracıllı̆ıyla güncellenmiştir (Karabacak, 2004: 48-49). Bu kapsamda $A B^{\prime}$ ye üye ülkelerde uygulanmakta olan güncel KDV oranlarına Tablo 1'de yer verilmektedir. 
Yegen, B. (2021). Avrupa Birliği'nde Katma Değer Vergisi Uyumlaştırması.

Fiscaoeconomia, 5(3), 1101-1116. Doi: 10.25295/fsecon.982198

\begin{tabular}{|c|c|c|c|c|}
\hline Üye Ülke & $\begin{array}{c}\text { Süper Indirilmiş } \\
\text { Oran }\end{array}$ & $\begin{array}{l}\text { Indirilmiş } \\
\text { Oran }\end{array}$ & Standart Oran & $\begin{array}{c}\text { Yaklaştırma } \\
\text { Oranı }\end{array}$ \\
\hline Almanya & - & 7 & 19 & - \\
\hline Avusturya & - & $10 / 13$ & 20 & 13 \\
\hline Belçika & - & $6 / 12$ & 21 & 12 \\
\hline Bulgaristan & - & 9 & 20 & - \\
\hline Çek Cumhuriyeti & - & $10 / 15$ & 21 & - \\
\hline Danimarka & - & - & 25 & - \\
\hline Estonya & - & 9 & 20 & - \\
\hline Fransa & 2,1 & $5,5 / 10$ & 20 & - \\
\hline Finlandiya & - & $10 / 14$ & 24 & - \\
\hline Hırvatistan & - & $5 / 13$ & 25 & - \\
\hline Hollanda & - & 9 & 21 & - \\
\hline İrlanda & 4,8 & $9 / 13,5$ & 23 & 13,5 \\
\hline İspanya & 4 & 10 & 21 & - \\
\hline İsveç & - & $6 / 12$ & 25 & - \\
\hline İtalya & 4 & $5 / 10$ & 22 & - \\
\hline Kıbrıs & - & $5 / 9$ & 19 & - \\
\hline Letonya & - & $5 / 12$ & 21 & - \\
\hline Litvanya & - & $5 / 9$ & 21 & - \\
\hline Lüksemburg & 3 & 8 & 17 & 14 \\
\hline Macaristan & - & $5 / 18$ & 27 & - \\
\hline Malta & - & $5 / 7$ & 18 & - \\
\hline Polonya & - & $5 / 8$ & 23 & - \\
\hline Portekiz & - & $6 / 13$ & 23 & 13 \\
\hline Romanya & - & $5 / 9$ & 19 & - \\
\hline Slovakya & - & 10 & 20 & - \\
\hline Slovenya & - & $5 / 9,5$ & 22 & - \\
\hline Yunanistan & - & $6 / 13$ & 24 & - \\
\hline
\end{tabular}

Kaynak: https://ec.europa.eu/taxation_customs/system/files/2021-06/vat_rates_en.xlsx

Tablo 1 incelendiğinde üye ülkelerde genellikle indirilmiş oran/oranlar ve standart oran uygulanmaktadır. Ancak İspanya, Fransa, İrlanda, İtalya ve Lüksemburg'da \%5 oranının altında süper indirilmiş oranların da uygulandığı görülmektedir. Süper indirilmiş oranlar, diğer ismiyle özel oranlar temel kuralların istisnaları olarak ifade edilmektedir. Söz konusu üye ülkelerin mevzuatlarını kademeli olarak uyumlaştırmalarına olanak sağlamak amacıyla geçiş dönemi için süper indirilmiş oran uygulamalarına izin verilmiştir (www.ec.europa.eu). Indirilmiş oranların Danimarka haricinde bütün üye ülkelerde uygulandıkları görülmektedir. Bazı üye ülkelerde sadece bir tane indirilmiş oran uygulanmasına rağmen çoğu üye ülkede iki farklı indirilmiş oran uygulanmaktadır. İndirilmiş oranlar, 28 Kasım 2006 Tarihli Konsey Direktifi Ek III'te tanımlanan belirli ürünlerle sınırlı olmakla birlikte söz konusu ürünlere insan ve hayvan tüketimine yönelik gıda maddeler, canlı hayvanlar, tohumlar, tıbbi malzeme, kitap, süreli yayın, otel konaklama, restoran ve yemek hizmetleri örnek olarak verilebilir (Hodzic ve Celebi, 2017: 82). Üye ülkelerde uygulanan standart oranların hepsinin 19 Ekim 1992 tarihli konsey direktifiyle 
Yegen, B. (2021). Avrupa Birliği'nde Katma Değer Vergisi Uyumlaştırması.

Fiscaoeconomia, 5(3), 1101-1116. Doi: 10.25295/fsecon.982198

belirlenen \%15 oranının üzerinde oldukları görülmektedir. Standart oranlar incelendiğinde en düşük oranının \%17 ile Lüksemburg'da, en yüksek oranın ise \%27 ile Macaristan'da uygulandığı anlaşılmaktadır. Bazı AB ülkelerinde KDV açısından uygulanan bir diğer oran ise yaklaştırma oranıdır. \%12'den az olmamak şartıyla yaklaştırma oranına bazı mal ve hizmetlerde standart bir tarifeye geçişi kolaylaştırmak için geçici olarak izin verilmiştir (Patterson, 2003: 10). Bu kapsamda özel düzenlemelere sahip yaklaştırma oranı uygulayan ülkeler; Belçika, İrlanda, Lüksemburg, Avusturya ve Portekiz'dir. Özetle birliğe üye bütün ülkelerin vergi sistemlerinde KDV uygulanmakta olup, uygulanmakta olan KDV oranları dikkate alındığında bütün uyumlaştırma çalışmalarına rağmen oranlar arasında hala önemli farklılıkların olduğu görülmekte, bu durum KDV'nin ülkelerdeki toplam vergi gelirleri içindeki paylarının ve vergi yükü farklılıklarının ortaya çıkmasına sebep olmakta, böylece uyumlaştırmanın tam anlamıyla sağlanamadığına işaret etmektedir (Yıldız, 2011: 126; Kozuharov vd., 2015: 256).

\section{Sonuç}

Ülkelerin sahip oldukları vergi sistemlerinden kaynaklanan farklılıkların işbirliği yapılmak suretiyle çözüme kavuşturulmaları şeklinde ifade edilebilen uyumlaştırma kavramı, günümüz ekonomik topluluklarından olup bağımsız uluslararası bir örgüt olarak faaliyet gösteren Avrupa Birliği açısından son derece önem arz etmektedir. Nitekim bu durum AB'nin kurucu antlaşmalarından biri olan Roma Antlaşması'nın vergi ile ilgili hükümlerinden de kolayca anlaşılmaktadır. Şöyle ki Roma Antlaşması'nın 93. maddesinde (eski 99. madde) dolaylı vergilerin uyumlaştırılmalarına yönelik düzenlemelerin yapılacağı açıkça ifade edilmiştir. $A B$ kuruluşundan itibaren malların, hizmetlerin, kişilerin ve sermayenin serbest dolaşabildiği tek pazar oluşturma amacıyla hareket ettiği için bu amacın gerçekleşmesinin önündeki en önemli engellerden biri olan vergilendirme alanındaki engelleri kaldırmak için uyumlaştırma çalışmaları üzerinde yoğunlaşmıştır. Uyumlaştırma çalışmalarında üye ülkelerdeki farklı vergi uygulamalarının fiyatlar üzerindeki doğrudan etkileri ve haksız rekabet ortamına zemin hazırlama ihtimalleri düşünülerek dolaylı vergilere, dolaylı vergiler içerisinden de ülkelerdeki hemen hemen bütün mal ve hizmet teslimlerini konusu içine alan KDV'ye öncelik verilmiştir.

KDV alanındaki uyumlaştırma çalışmalarında temel hukuki norm olarak konsey direktifleri kullanılmaktadır. 1967 yılında yayınlanan birinci ve ikinci konsey direktifleri ortak KDV sisteminin oluşturulmasına yönelik başlangıç hükümlerini içermekte olup, söz konusu direktiflerde ortak KDV sisteminin genel hatlarından bahsedilmiş, ayrıntılı düzenlemelere yer verilmemiştir. 1977 yılında yayınlanan altıncı konsey direktifi KDV uyumlaştırması açısından çok önemli bir yere sahiptir. Şöyle ki altıncı direktifte birinci ve ikinci direktiflerin aksine ortak KDV sistemine ilişkin olarak bir vergide olması gereken temel unsurlar açıkça belirlenmiştir. Ayrıca söz konusu direktifte büyün üye ülkelerin en geç 1 Ocak 1978 tarihine kadar KDV'ye geçişlerini içeren mevzuat değişikliklerini tamamlanmaları gerektiği ifade edilmiş, standart oranın haricinde artırımış veya indirilmiş oranların uygulanabileceğine işaret edilerek ilk kez oranlarla ilgili kısmi de olsa açıklamaya yer verilmiştir. KDV uyumlaştırması konusunda konsey tarafından yayınlanan bir diğer direktif 16 Aralık 1991 tarihli konsey direktifi olmuştur. 1985 yılında yayınlanan Beyaz Kitap ve 1987 yılında yayınlanan Tek Senet'e müteakip yayınlanan söz konusu direktifle ortak KDV sistemini tamamlamak ve mali sınırları ortadan kaldırımak amacıyla altıncı direktifte değişiklikler yapılmıştır. Uyumlaştırma kapsamında ortak KDV sisteminde uygulanması öngörülen oranlarla ilgili açılamalara ise ilk defa 19 Ekim 1992 tarihli 
Yegen, B. (2021). Avrupa Birliği'nde Katma Değer Vergisi Uyumlaştırması. Fiscaoeconomia, 5(3), 1101-1116. Doi: 10.25295/fsecon.982198

konsey direktifinde açık bir şekilde yer verilmiştir. Şöyle ki ilgili direktifte KDV açısından standart oranın \%15'ten aşağı olmaması, en fazla iki tane indirilmiş oran uygulanabileceği ve indirilmiş oranların da \%5'ten aşağı olmamaları gerektiği, bunların yanı sıra bazı üye ülkelerin geçiş dönemi sürecinde süper indirilmiş oran, sıfır oran ve yaklaştırma oranı uygulayabilecekleri ifade edilmiştir. Ayrıca direktifte "Lüks" veya daha yüksek oranların kaldırılmaları gerektiğine de işaret edilmiştir. $A B^{\prime}$ de ortak KDV sistemi üzerinde belirleyici bir etkiye sahip olan direktiflerden biri de 28 Kasım 2006 tarihli konsey direktifidir. Söz konusu direktifle birliğin günümüzde uygulamakta olduğu ortak KDV sisteminin adeta omurgası oluşturulmuştur. Bu kapsamda ilgili direktifle KDV sistemi açısından hayati öneme sahip altıncı direktif yürürlükten kaldırılmış ve sistemi bir bütün haline getirecek şekilde sisteme netlik kazandırılmıştır. Takip eden yıllarda AB'de ortak KDV sistemine ilişkin yapılan düzenlemeler 28 Kasım 2006 tarihli konsey direktifi üzerinden yapılmıştır ve yapılmaya da devam edecektir. Diğer bir ifadeyle günümüz $A B$ ortak KDV sisteminin temelini 28 Kasım 2006 tarihli konsey direktifi oluşturmaktadır.

$A B^{\prime}$ de KDV alanındaki uyumlaştırma çalışmaları uzun zamandır sürmekte olup bir nevi çalışmaların sonucu niteliğindeki üye ülkelerde geçerli olan KDV oranlarına Tablo 1'de yer verilmiştir. Üye ülkelerden sadece Danimarka'da standart oran uygulanmakta olup, diğer üye ülkelerin hepsinde standart oranın yanı sıra bir veya iki tane indirimli oran uygulanmaktadır. Uygulanmakta olan standart ve indirimli oranların ise ortak KDV sistemine ilişkin yayınlan direktiflerle uyumlu olduğu anlaşılmaktadır. Standart ve indirimli oranların dışında sınırlı sayıda üye ülkenin süper indirimli oran ve/veya yaklaştırma oranı kullandığı da görülmektedir. Genel kuralların istisnaları olarak adlandırılan bu oranların uygulanmaları konusunda söz konusu ülkelere geçici olarak izin verildiği bilinmektedir. Özetle $A B$, ortak pazar hedefi doğrultusunda KDV'nin uyumlaştırılmasında önemli ölçüde ilerleme kaydetmiştir, ancak üye ülkeler arasındaki gerek standart gerek indirilmiş oran uygulamaları arasındaki farklılıklar ve bazı ülkelere tanınan süper indirimli ve/veya yaklaştırma oranları yoğun bir şekilde gerçekleştirilen uyumlaştırma çalışmalarına rağmen uyumlaştırmanın tam anlamıyla sağlanamamış olduğuna işaret etmektedir. Bu nedenle tarafsız bir rekabet ortamından söz edebilmek için süper indirimli ve yaklaştırma oranlarının kısa zamanda uygulamadan kaldırılmalarına ve hâlihazırda üye ülkeler arasındaki hem standart oran hem de indirilmiş oran farklılıklarının minimum düzeye getirilmelerine ihtiyaç duyulmaktadır.

\section{Kaynakça}

Albayrak, M. ve Yurdadoğ, V. (2017). Avrupa Birliği'nde Vergi Uyumlaştırması ve Vergi Rekabeti. Sosyo-Ekonomik Stratejiler V Türk Dünyası Araştırmaları içinde (ss. 49-84). London: IJOPEC Publication Limited.

Alganer, Y. ve Yılmaz, G. (2010). Avrupa Birliği Müktesebatı Bağlamında Katma Değer Vergisi'nde Yakınlaştırma ve Uyumlaştırma Çalışmaları, Marmara Üniversitesi İktisadi ve İdari Bilimler Dergisi, 28(1), 135-60.

Altunay, E. (2010). Avrupa Birliği Vergi Politikası ve Türkiye'nin Uyum Sürecinin Değerlendirilmesi, Bütçe Dünyası Dergisi, S:34(2010/2)

Avrupa Birliğinin Tarihçesi, T.C. Dışişleri Bakanlığı Avrupa Birliği Başkanlığı, https://www.ab.gov.tr/p.php?e=105 Erişim Tarihi: 30.07.2021 
Bilici, N. (2007). Avrupa Birliği-Türkiye İlişkileri, Ankara: Seçkin Yayıncılık.

Erkan, F. (2009). Avrupa Birliğinde Dolaysız Vergilerin Uyumlaştırılması ve Avrupa Birliği Mahkemesinin Bu konudaki Rolü, Ankara: T.C. Maliye Bakanlığı Strateji Geliştirme Başkanlığı Yayınları, Yayın No: 2009/399.

Güçlü, E. B. (2012). Avrupa Birliği'nde KDV Uygulaması-I: Genel Usul ve Esaslar, Vergi Sorunları, Sayı 281, 133-140.

Güngör, K. (2001). Avrupa Birliği'nde Vergi Uyumlaştırması ve Vergi Uyumlaştırma Politikası, Maliye Dergisi, Sayı 136, 49-76.

Hodzic, S. and Celebi, H. (2017). Value-Added Tax and Its Efficiency: EU-28 and Turkey, UTMS Journal of Economics, 8(2), 79-90.

Karabacak, H. (2004). Avrupa Birliği'nde Katma Değer Vergisinin Oran Yapısı, Maliye Dergisi, Sayı 147. 46-56.

Karolak, A. (2011). Adaptation Process of a Polish Tax Law to European Union Norms Harmonization of a Value Added Tax, Economics \& Sociology, 4(1), 54-63.

Kozuharov, S., Ristovska, N. and Ilieva, J. (2015). Harmonization of Tax Policies: Reviewing Macedonia and Croatia, UTMS Journal of Economics, 6(2), 255-265.

Matei, G. ve Pirvu, D. (2011). Reasons for Tax Harmonization in the EU, Finance-Challenges of the Future, 11(13), 66-75.

Nerudová, D. (2004). Tax Competition and Tax Harmonization in The European Union. Acta Universitatis Agriculturae et Silviculturae Mendelianae Brunensis, 52(6), 135-144.

Oral, H. (2005). Avrupa Birliği'ndeki Vergi Uyum Çalışmaları ve Türkiye, Türkiye Barolar Birliği Dergisi, Sayı 56, 261-280.

Oręziak, L. (2020). The Evolution of the Process of the Harmonization of Value Added Tax (VAT), Studia Europejskie - Studies in European Affairs, 24(4), 93-108.

Patterson, B. (2003). The Rates of VAT, Directorate General for Research, Luxembourg: European Parliament.

Pehlivan, O. ve Öz, E. (2015). Uluslararası Vergilendirme, Celepler Matbaacılık: Trabzon.

Safonova, M.F. vd. (2016). Taxes Harmonization Features in the European Union Countries, International Journal of Economics and Financial Issues, 6 (S8), 154-159.

Saraçoğlu, F. ve Ejder H. (2002). Katma Değer Vergisinde Varış Ülkesinde veya Menşe Ülkesinde Vergilendirme ve İhracat İstisnası, Dokuz Eylül Üniversitesi Iktisadi ve Idari Bilimler Fakültesi Dergisi. 17(1), 61-80.

Saraçoğlu, F. (2006). Avrupa Birliği Vergi Uyumlaştırma Süreci ve Türkiye, Ankara: Maliye ve Hukuk Yayınları.

Ünsal, H. ve Ubay, B. (2018). Avrupa Birliği KDV Tevkifatı Mekanizmasının Türk KDV Sistemindeki KDV Tevkifatı Müessesesi ile Karşılaştırılması, Maliye Dergisi, Sayı 175, 275-298. 
Yegen, B. (2021). Avrupa Birliği'nde Katma Değer Vergisi Uyumlaştırması. Fiscaoeconomia, 5(3), 1101-1116. Doi: 10.25295/fsecon.982198

Yazarkan, H. ve Mezararkalı, P. (2015). Avrupa Birliği ve Türkiye illişkilerinde Doğrudan Vergi Uygulamaları, Ordu Üniversitesi Sosyal Bilimler Enstitüsü Sosyal Bilimler Araştırmaları Dergisi, 5(13), 64-76.

Yıldız, M. (2004). Avrupa Birliği'nde Maliye Politikası ve Türkiye Açısından Bir Değerlendirme, Alfa Aktüel Kitabevi.

Yıldız, H. (2006). Avrupa Birliği Vergi Politikası ve Vergi Uyumlaştırma Çalışmaları, Erzincan Üniversitesi Hukuk Fakültesi Dergisi, 10(3-4), 549-569.

Yıldız, H. (2011). Avrupa Birliği'nde Maliye Politikalarının Uyumlaştırılması, Çukurova Üniversitesi Sosyal Bilimler Enstitüsü Dergisi, 20(2), 111-133.

First Council Directive 67/227/EEC of 11 April 1967, https://op.europa.eu/en/publicationdetail/-/publication/93de7850-0dba-4bdb-a393-b09653120da6/language-en Erişim Tarihi: 29.07.2021

Second Council Directive 67/228/EEC of 11 April 1967, https://op.europa.eu/en/publicationdetail/-/publication/99ab67a1-f672-4605-8a30-c93cf82973de/language-en Erişim Tarihi: 29.07.2021

Sixth Council Directive 77/388/EEC of 17 May 1977, https://eur-lex.europa.eu/legalcontent/EN/TXT/PDF/?uri=CELEX:31977L0388\&from=GA Erişim Tarihi: 29.07.2021

Council Directive 91/680/EEC of 16 December 1991, https://eur-lex.europa.eu/legalcontent/EN/TXT/PDF/?uri=CELEX:31991L0680\&from=en Erişim Tarihi: 29.07.2021

Council Directive 92/77/EEC of 19 October 1992, https://eur-lex.europa.eu/legalcontent/EN/TXT/PDF/?uri=CELEX:31992L0077\&from=EN Erişim Tarihi: 04.08.2021

Council Directive 2006/112/EC of 28 November 2006, https://eur-lex.europa.eu/legalcontent/EN/TXT/PDF/?uri=CELEX:32006L0112\&from=EN Erişim Tarihi: 06.08.2021

VAT Rates, European Commission, Taxation and Customs Union, Exceptions to the rules "special rates" of VAT, https://ec.europa.eu/taxation_customs/vat-rates_en Erişim Tarihi: 06.08.2021

White Paper \& List of White Papers, https://eurlex.europa.eu/summary/glossary/white_paper.html Erişim Tarihi: 30.07.2021

Etik Beyanı: Bu çalışmanın tüm hazırlanma süreçlerinde etik kurallara uyulduğunu yazar beyan eder. Aksi bir durumun tespiti halinde Fiscaoeconomia Dergisinin hiçbir sorumluluğu olmayıp, tüm sorumluluk çalışmanın yazarına aittir.

Ethics Statement: The author declares that ethical rules are followed in all preparation processes of this study. In case of detection of a contrary situation, Fiscaoeconomia has no responsibility and all responsibility belongs to the author of the study. 
Yegen, B. (2021). Avrupa Birliği'nde Katma Değer Vergisi Uyumlaştırması.

Fiscaoeconomia, 5(3), 1101-1116. Doi: 10.25295/fsecon.982198

Value Added Tax Harmonization in the European Union

Baki YEGEN

\section{Extended Abstract}

Tax harmonization means that countries with different tax systems converge their legislation in order to act jointly in the tax sense. Because different tax systems are likely to lead to unfair tax competition. For this reason, the concept of tax harmonization in economic communities acting jointly is emphasized. Otherwise, the possibility of moving taxable elements to countries where taxes are applied at a lower rate is high. Taxation is considered as one of the basic elements of economic integration in the European Union, which is an independent supranational economic community where an impartial competitive environment is adopted. Therefore, the concept of tax harmonization is an important part of the economic integration that the European Union is trying to achieve. The European Union has aimed at the free movement of goods, services, persons and capital in member states, which are expressed as four freedoms. Tax harmonization is needed in order to achieve this target. As a matter of fact, it is easily understood from the taxation provisions of the Treaty of Rome (1957), which is one of the founding treaties of the union, that the European Union has acted for this purpose since its establishment. That is to say, in Article 93 of the Treaty of Rome (former Article 99), it is clearly stated that harmonization can be made in the field of indirect taxes to the extent necessary for the establishment and functioning of the internal market. Thus, the European Union has signaled that it will focus on indirect taxes in tax harmonization. As a matter of fact, tax harmonization studies in the European Union have progressed in this direction. Since it has a reduction mechanism within the scope of tax harmonization studies, Value Added Tax was accepted as a common expense tax and the cascade tax system applied in most of the member countries was abandoned. As it is understood, the harmonization of Value Added Tax among indirect taxes has been given priority in the European Union. The reasons behind the preference for value added tax are that it has a discount mechanism, has a decisive effect on prices and has a wide tax base. In short, the advantages of value added tax caused it to be chosen as a common expense tax. Value added tax is collected over the added value created at every stage of the economic process from production to consumption and covers almost all goods delivery and services, with exceptions. It also allows sellers to deduct the taxes they pay on purchases from the taxes they collect on their sales. In the European Union, value added tax was preferred and the negativities arising from the tax system differences of the member countries were tried to be eliminated. Directives published by the council draw attention in harmonization studies on value added tax in the European Union.

The directives adopted by the council in the harmonization studies for value added tax in the European Union draw attention. At this point, many directives related to value added tax have been accepted from the past to the present and will continue to be accepted in the future. Among the directives adopted so far, the first council directive, the second council directive, the sixth council directive, the council directive of 16 December 1991, the council directive of 19 October 1992 and the council directive of 28 November 2006 come to the fore. In other words, the aforementioned directives were decisive in the creation of the common value added tax system. In this context, two council directives, the first and the second, were 
Yegen, B. (2021). Avrupa Birliği'nde Katma Değer Vergisi Uyumlaştırması. Fiscaoeconomia, 5(3), 1101-1116. Doi: 10.25295/fsecon.982198

published in 1967. In the first council directive, it was stated that the member countries of the union should abandon different tax types and adopt the common value added tax system and change their legislation according to the common value added tax system. In the second council directive, the basic elements of the tax related to the value added tax were included, but detailed explanations were not made. In the sixth council directive, the basic elements of the tax related to the value added tax were included, but unlike the second council directive, detailed explanations were made. In addition, it was stated that the member states should complete the legislative changes by 1 January 1978 at the latest. With the aforementioned directive, it was stated that in addition to the standard rate, member countries could apply increased or reduced rates in some cases, but limits on rates were not determined. The White Paper published in 1985 and the Single Act that entered into force on 1 July 1987 were effective in the preparation of the council directive dated 16 December 1991 . With the council directive dated 16 December 1991, some articles of the sixth council directive were amended and the common value added tax system was tried to be completed. The council directive dated 19 October 1992 had a very important role in the rate harmonization of value added tax. With the said directive published just before the transition to the Customs Union, limits were drawn for the rates of the common value added tax system for the first time. In this context, some articles of the sixth council directive were amended once again. In this context, it has been stated that the standard value added tax rates of the member countries cannot be less than $15 \%$. In addition, it was stated that the member countries of the union can apply a maximum of two reduced rates, not less than $5 \%$. It has also been stated that some countries may apply zero rate, super reduced rate and "parking rate" during the transition period. The council directive of 28 November 2006 also has an important role in terms of the common value added tax system. The said directive has been decisive on the common value added tax system being implemented today. With the directive, the sixth council directive was repealed and the common value added tax system was simplified. The council directive of 28 November 2006 formed the basis of the common value added tax system. The next changes made on the common value added tax system were made on the basis of the legislation determined by the council directive dated 28 November 2006.

The acceptance of the value added tax system in the European Union as the common expenditure tax of the union necessitated harmonization in terms of value added tax rates. Because, in case of large differences between the rates applied in the member states, the free movement of goods, services, persons and capital is endangered. For this reason, approximation of value added tax rates in member countries has been seen as a priority target. Today, in the European Union, which consists of twenty-seven member countries, it is understood that the rules determined in the council directive dated 19 October 1992 regarding the rates are observed in general. In Denmark, the reduced rate is not applied, only the standard rate is applied. All member states except Denmark apply a standard rate above $15 \%$ and one or two reduced rates above $5 \%$. A super reduced rate of less than $5 \%$ applies in Spain, France, Ireland, Italy and Luxembourg. In addition, a "parking rate" of less than 15\% applies in Austria, Luxembourg, Ireland and Portugal. In some countries, the super reduced rate and parking rate applied for certain goods are expressed as the rates adopted for the transition period. Therefore, it is foreseen that the super reduced rate and the parking rate will be abolished in the future. Although significant progress has been made as a result of 
harmonization efforts regarding value added tax in the European Union, it is seen that there are still significant differences between the rates applied by the member states. In order to ensure an impartial competitive environment, it is necessary approximation of the value added tax rates as close as possible and abolishing the super reduced rate and parking rate granted to some countries as soon as possible. 